\title{
PIV Measurements of the CEV Hot Abort Motor Plume for CFD Validation
}

\author{
Mark Wernet ${ }^{*}$ \& John D. Wolter \\ NASA Glenn Research Center \\ Cleveland, Ohio \\ Randy Locke ${ }^{\dagger}$ \& Adam Wroblewski ${ }^{\ddagger}$ \\ ASRC, Inc. \\ Cleveland, Ohio \\ Robert Childs ${ }^{\S}$ \& Andrea Nelson ${ }^{\S}$ \\ Eloret Corporation \\ Moffett Field, California
}

NASA's next manned launch platform for missions to the moon and Mars are the Orion and Ares systems. Many critical aspects of the launch system performance are being verified using computational fluid dynamics (CFD) predictions. The Orion Launch Abort Vehicle (LAV) consists of a tower mounted tractor rocket tasked with carrying the Crew Module (CM) safely away from the launch vehicle in the event of a catastrophic failure during the vehicle's ascent. Some of the predictions involving the launch abort system flow fields produced conflicting results, which required further investigation through ground test experiments. Ground tests were performed to acquire data from a hot supersonic jet in cross-flow for the purpose of validating CFD turbulence modeling relevant to the Orion Launch Abort Vehicle (LAV). Both 2component axial plane Particle Image Velocimetry (PIV) and 3-component cross-stream Stereo Particle Image Velocimetry (SPIV) measurements were obtained on a model of an Abort Motor (AM). Actual flight conditions could not be simulated on the ground, so the highest temperature and pressure conditions that could be safely used in the test facility (nozzle pressure ratio 28.5 and a nozzle temperature ratio of 3 ) were used for the validation tests. These conditions are significantly different from those of the flight vehicle, but were sufficiently high enough to begin addressing turbulence modeling issues that predicated the need for the validation tests.

\section{Nomenclature}

AAPL Aero-Acoustic Propulsion Laboratory

AM Abort Motor

CEV Crew Exploration Vehicle

CFD Computational Fluid Dynamics

CM Crew Module

$\mathrm{C}_{\mathrm{x}} \quad$ Axial force coefficient

HFJER High Flow Jet Exit Rig

LAV Launch Abort Vehicle

NATR Nozzle Aeroacoustic Test Rig

PIV Particle Image Velocimetry generic label for the technique

SPIV Stereo Particle Image Velocimetry, 3-velocity component configuration

\section{Introduction}

A ccurate prediction of aerodynamic forces on the Ares Launch Abort Vehicle (LAV) is critical for determining both the environmental impact on the Crew Exploration Vehicle (CEV) crew and the trajectory of the vehicle.

\footnotetext{
* Senior Research Engineer, Optical Instrumentation Technology and NDE Branch, Associate Fellow AIAA

${ }^{\bullet}$ Research Engineer, Inlet and Nozzle Branch, Associate Fellow AIAA

† Senior Research Engineer, Optical Instrumentation Technology and NDE Branch

${ }^{\ddagger}$ Research Engineer, Optical Instrumentation Technology and NDE Branch

$\S$ Scientist, Eloret Corp., Member AIAA

$\diamond$ Research Scientist, Eloret Corp., Senior Member AIAA
} 
CFD predictions of complex flow fields are routinely used in the design of complicated aerospace vehicles, however application of different turbulence models in this case resulted in very different axial force estimates. Simulations by researchers at NASA Ames Research Center of the LAV 606-068 configuration (rocket tower, two abort motors and capsule) were run at an angle of attack of $20^{\circ}$, and a flight Mach number of 0.3 with the abort motors firing at $100 \%$ power. The cases run and their resulting axial force coefficients $\left(\mathrm{C}_{\mathrm{x}}\right)$ are summarized in :

Table 1. LAV CFD Predictions

\begin{tabular}{|l|c|l|}
\hline Code Version & Turbulence Model & $\mathrm{C}_{\mathrm{x}}$ \\
\hline Overflow 2.0aa "Lag_Robusta” & Lag & 1.8 \\
\hline Overflow 2.0aa & SST & 0.8 \\
\hline Overflow 2.0aa “Lag_Robusta” & SST & 0.7 \\
\hline Overflow 2.0aa & Baldwin-Barth & 0.6 \\
\hline
\end{tabular}

The large difference between the results from the Lag turbulence model compared to those of other turbulence models raised doubts about the accuracy of the predictions. Further investigation revealed that the mechanism for the higher force appears to be energy transferred from the AM plumes into the freestream which flows past the plumes and impinges on the LAV capsule. The drag force appeared to be dependent on the jet temperature and hence velocity, for the fixed Mach number jet. These physical mechanisms could reasonably be the source of the increased drag, and this raised the concern that jet temperature was an important parameter in the problem. A substantial amount of wind tunnel testing of LAV aerodynamics were run with jet plumes significantly cooler than the flight vehicles, which did not reveal this temperature dependence.

An experiment was required to provide a benchmark dataset for assessment of the different CFD predictions. The CFD researchers were interested in understanding how to predict jet in cross-flow flow phenomena so the entire LAV system (rocket and capsule assembly) was not tested - only a single Launch Abort Motor. Key features of the experiment included a freestream flow, a high temperature, high pressure jet at an angle to the freestream, a capsulelike shape on which pressures could be recorded, and a means for measuring detailed flowfield characteristics of the plume and surrounding air. The AeroAcoustic Propulsion Laboratory (AAPL) at NASA Glenn Research Center (GRC) was chosen as the site of this experiment based on its suitability for PIV measurements and its ability to produce a high temperature plume. However, the facility is not capable of pressures and temperatures as great as in the AM, so CFD studies were performed in order to confirm that an experiment in this facility would provide a test case to illustrate the differences in the two model predictions. To that end, both 2-component axial plane Particle Image Velocimetry and 3-component cross-stream Stereo Particle Image Velocimetry measurements were obtained on a model of the AM within the AAPL. The axial and cross-stream PIV results are compared to two different turbulence model predictions.

\section{Equipment and Procedures}

The experiment was conducted in the AAPL at the NASA GRC. The AAPL is an acoustic test facility housed in a $65 \mathrm{ft}$. radius acoustically lined dome. Three active test rigs are housed in the AAPL. For this experiment the Nozzle Aeroacoustic Test Rig (NATR) ${ }^{1}$ was used. The NATR is a 53 inch diameter freejet rig capable of freestream velocities up to Mach 0.3. Housed within the NATR is a jet engine simulator called the High Flow Jet Exit Rig (HFJER). Figure 1 depicts the NATR and HFJER within the AAPL facility.

The HFJER has been previously used to test nozzles with exit areas of 10-20 in ${ }^{2}$ in single flow configuration with heated flow at nozzle pressure ratios up to 4, temperatures up to $1900 \mathrm{R}$ and flow rates up to $29 \mathrm{lbm} / \mathrm{sec}$. For the CEV AM test, the rig was modified to provide flow at a nozzle pressure ratio of 28.5 and temperature up to $1460 \mathrm{R}$, but at a significantly lower flow rate of approximately $1 \mathrm{lbm} / \mathrm{sec}$. The cold, $450 \mathrm{psig}$ supply air to the HFJER was heated using a natural gas combustor.

Figure 2 shows the model configuration. A "mini-strut" and "mini-sting" attach to the HFJER sting, supplying heated air to the nozzle. Three nozzle configurations were built, directing the jet $0^{\circ}, 25^{\circ}$, and $40^{\circ}$ above the free-jet axis. The angled jet flow travels past a capsule shape, not striking the capsule, but passing close enough that freestream flow striking the capsule interacts with the jet shear layer before reaching the capsule. The nozzles were instrumented with a static pressure tap and a thermocouple upstream of the nozzle throat. 


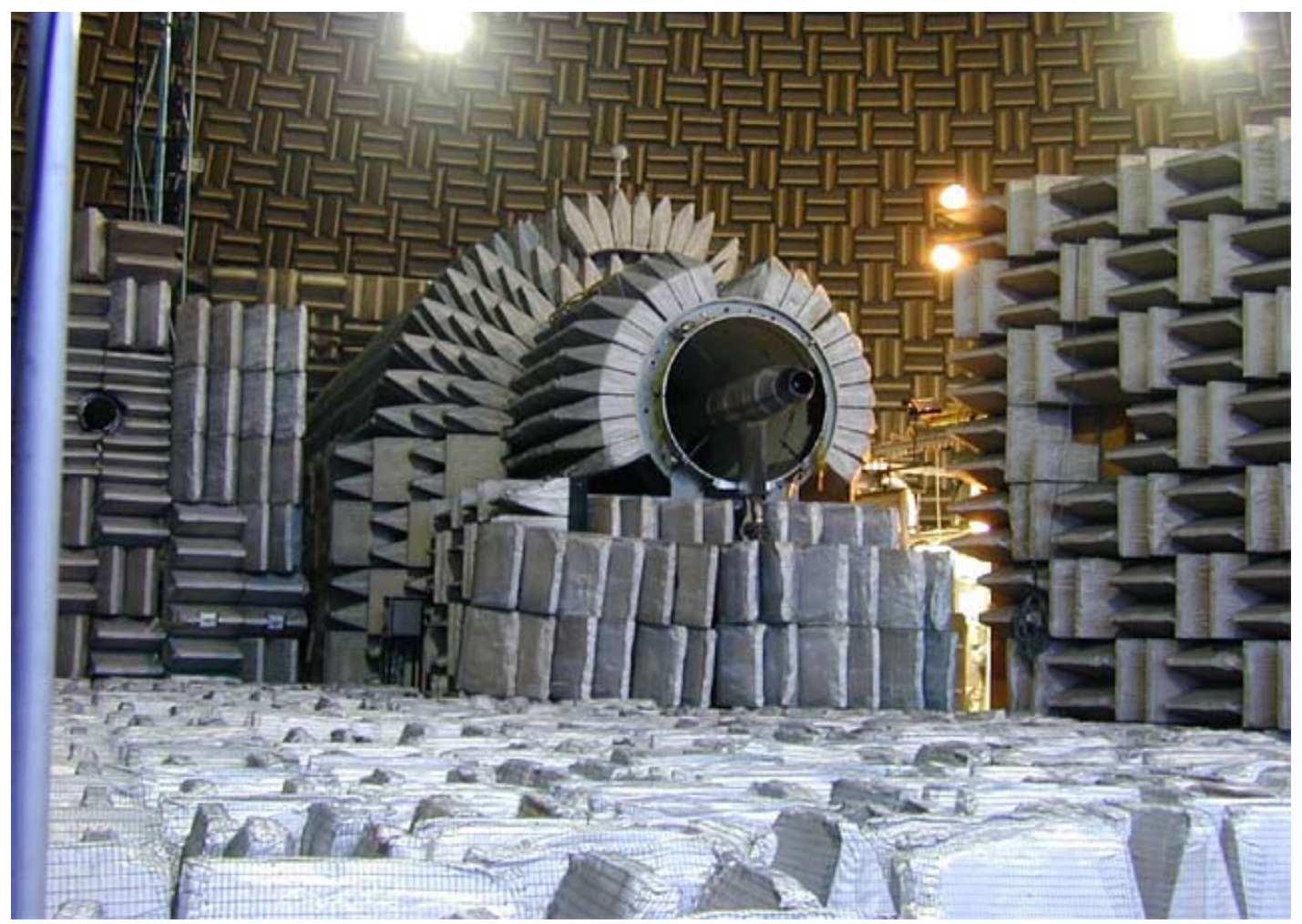

Figure 1: Nozzle Aeroacoustic Test Rig (NATR) inside the AeroAcosustic Propulsion Lab.

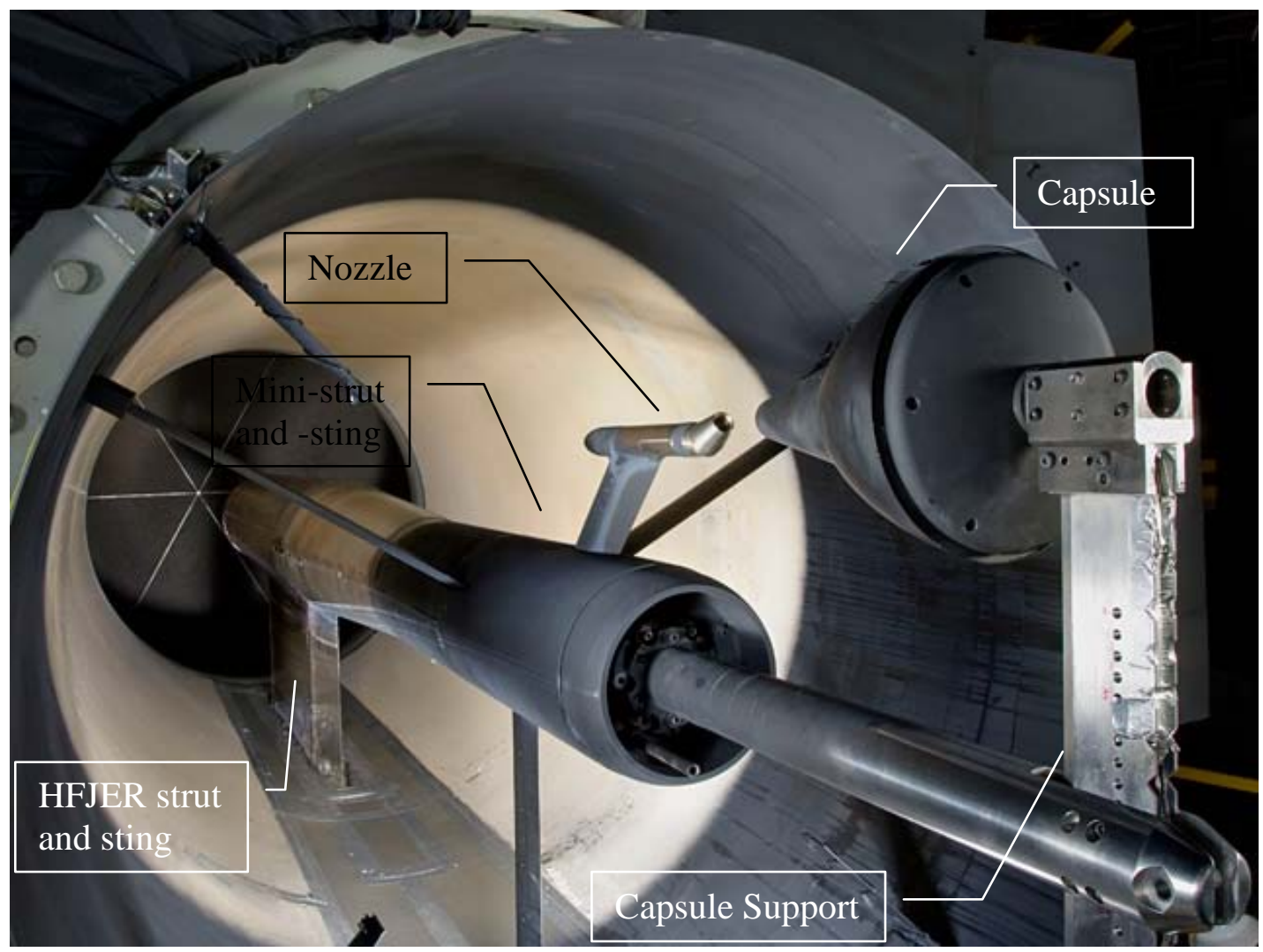

Figure 2: 85-AA CEV Model in the NATR. Tests were performed with and without the capsule in place. 
The 85-AA capsule was a 4\% scale model of the ALAS 11 rev3c without the umbilical cutout or the tower. A strut extended from the base of the HFJER to support the capsule model. The design of the support strut allowed for the repositioning of the capsule as needed. Two sets of bolt holes at the connection between the capsule and the support strut allowed the capsule to be mounted with its axis at $0^{\circ}$ (for the $25^{\circ}$ nozzle) and $15^{\circ}$ (for the $40^{\circ}$ nozzle) relative to the freejet axis.

For each configuration, the tunnel was operated long enough to reach thermal equilibrium, and then SPIV data were acquired. Steady-state data, such as test conditions and capsule pressures, were recorded nearly instantaneously. A plane of SPIV data required approximately two minutes of sampling to obtain a valid statistical sample. A recording of the steady state data was taken for each plane of SPIV data recorded. During operations, the primary test conditions were continuously monitored to ensure that test conditions remained consistent throughout a test configuration. A total of 8 configurations were tested, as shown in Table 2 . The $0^{\circ}$ nozzle case was a control case for comparison with other historical jet flow data sets.

Table 2. 85-AA Configurations Tested

\begin{tabular}{|c|c|c|}
\hline Nozzle & $\begin{array}{c}\text { Model } \\
\text { Configuration }\end{array}$ & PIV Configuration \\
\hline $0^{\circ}$ & Nozzle Only & Cross-Stream \\
\hline $25^{\circ}$ & Nozzle Only & Cross-Stream \\
\hline $25^{\circ}$ & Nozzle Only & $\begin{array}{c}\text { Cross-Stream, } \\
\text { Small Field of View }\end{array}$ \\
\hline $25^{\circ}$ & Nozzle Only & Streamwise \\
\hline $25^{\circ}$ & Nozzle/Capsule & Cross-Stream \\
\hline $40^{\circ}$ & Nozzle Only & Cross-Stream \\
\hline $40^{\circ}$ & Nozzle Only & Streamwise \\
\hline $40^{\circ}$ & Nozzle/Capsule & Cross-Stream \\
\hline
\end{tabular}

\section{Particle Image Velocimetry System}

The Stereo Particle Image Velocimetry (SPIV) system was configured to provide cross-stream measurements of the 3-component velocity field from the test article. The entire SPIV system was mounted on a large traverse system to facilitate performing velocity plane surveys of the flow field, see figure 3. The SPIV system employed two high resolution (4008x2672 pixels) cameras to provide a 300x360 mm field of view. The cameras were mounted downstream of the model exit plane at $\pm 45^{\circ}$ from the nozzle centerline. The measurement plane was illuminated using a dual head $400 \mathrm{~mJ} / \mathrm{pulse} \mathrm{Nd}$ :YAG laser system. The laser beams were formed into $1 \mathrm{~mm}$ by $350 \mathrm{~mm}$ light sheets using cylindrical and spherical lenses. Both cameras were connected to a single computer system and the data was acquired continuously and streamed to disk at a rate of 2 frame pairs/camera/sec.

The large field of view for the PIV system was required in order to be able to capture the angled nozzle plume over a range of $20+$ diameters downstream from the nozzle exit plane. In addition to the cross-stream planes, the SPIV system was reconfigured on the final test day to acquire 2-component axial plane slices of the nozzle flow. Here the light sheet optics were rotated $90^{\circ}$ and the cameras were mounted on the side of the large traverse. The field of view of the 2-D PIV system was nominally the same for the axial plane measurements as that used in the cross-stream SPIV configuration.

\section{Flow Seeding}

For PIV, the fluid motion being measured is marked by the use of particles introduced into the flow. These particles must be sufficiently small so they will have no slip relative to the fluid (so that their motion is the same as the fluid motion). In addition, all fluid must be laden with particles at a concentration high enough that sufficient particles (510) are found in an interrogation region of the recorded PIV images. In these tests we are mixing two fluids: the core stream and the free-jet flow. It is also crucial that the seed be fully mixed and dispersed in the flow before the 
measurement region in order to assure good quality PIV images. Finally, the seed must not be affected by the high temperatures of the gas; this is especially true of the seed in the core stream at $520 \mathrm{C}$.

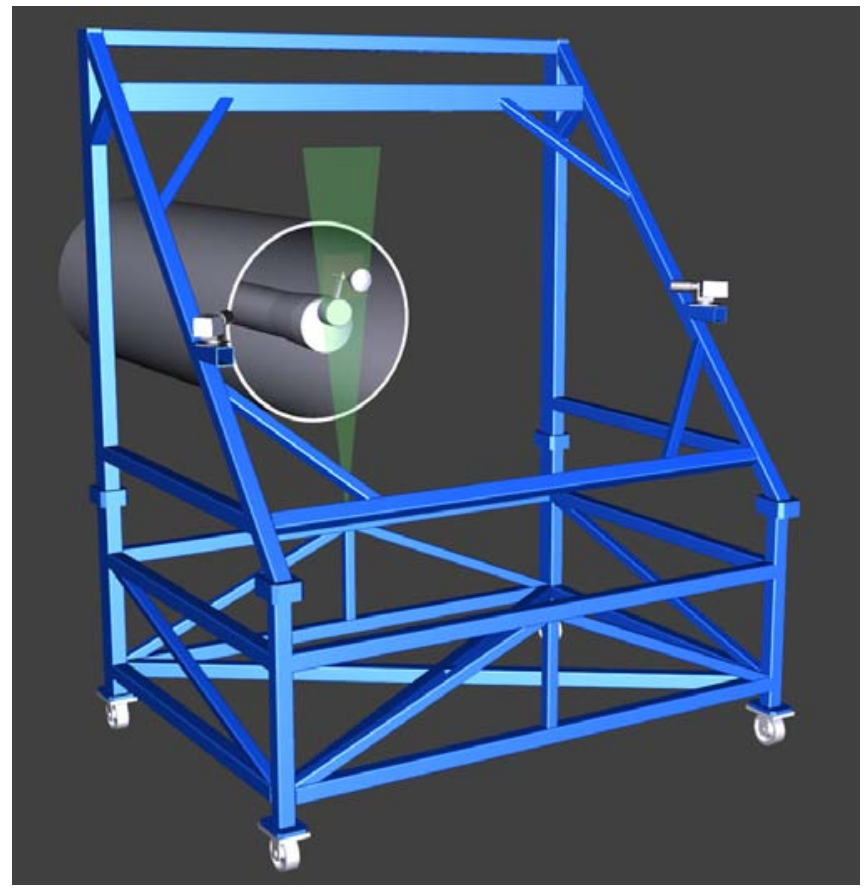

Figure 3: Stereo PIV system installation on a large blue traverse frame used to obtain velocity surveys of the jet flow.

Two independent seeding systems were required in this study. The hot nozzle flow was seeded with a refractory seed material and the ambient air was seeded using a commercial smoke generator. The refractory seed material used for the jet flow was $0.5 \mu \mathrm{m}$ diameter alumina powder. A dispersion of the alumina seed material in ethanol was prepared using a $\mathrm{pH}$ stabilization technique. ${ }^{2}$ The alumina/ethanol dispersion was dispersed in the flow well upstream of the nozzle using an air-assisted atomizing nozzle. The $\mathrm{pH}$ stabilization technique provides highly dispersed, unagglomerated seed particles in the flow. The ambient free-jet flow was seeded using a propylene glycol liquid seed material. Several fog generators were setup in the inlet tunnel to the free-jet - allowing nearly 60 feet of mixing before entering the SPIV measurement plane.

\section{PIV Data Processing}

The PIV image data were processed using multi-pass correlation with 64x64 pixel subregions on 32 pixel centers, followed by $32 \times 32$ pixel subregions on 16 pixels centers. Subregion distortion processing was also used to process the PIV data. ${ }^{3}$ Subregion distortion was used to correct for velocity gradients across the subregion and to minimize the "peak-locking" effect, which is the tendency for the estimated particle displacements to preferentially concentrate at integer values. In the subregion distortion technique, the local velocity gradients surrounding the current correlation subregion are used to distort the subregion before the cross-correlation processing operation. Distorting the subregion yields correlation subregions with uniform particle displacements, and hence, reduces any bias caused by the velocity gradients. Typically two additional passes after the multi-pass processing are used with subregion distortion applied to refine the correlation peak estimates. Due to the oblique viewing of the model in the stereo PIV configuration, the nozzle was recorded in both the left and right camera views. The image of the nozzle corrupts the background in the image - leading to a loss of correlation in regions where the model is brightly illuminated by the laser light sheet. The Symmetric Phase Only Filtering (SPOF) technique was also applied in the data processing to mitigate any effects from the model being in the background of the images near the exit plane. ${ }^{4}$ The final velocity vector maps had $1 \mathrm{~mm}$ spatial resolution. Sequences of 400 velocity vector maps were acquired at each measurement station and ensemble averaged to provide first and second order statistics over the entire measurement plane. Chauvenet's criteria was used to eliminate any outliers in the ensemble averaging process. ${ }^{5}$ All of the processed PIV data were placed in the nozzle coordinate system and transferred to NASA Ames for comparison with CFD predictions. 


\section{Results \& Discussion}

\section{A. PIV Measurements}

Figures 4 and 5 show velocity contours for the $25^{\circ}$ and $40^{\circ}$ nozzles, respectively, as viewed from the side. The color contours represent velocity magnitude and the model of the nozzle has been inserted for reference. This data represents the measurements acquired on the last test day, where 2-D PIV data were acquired. Figure 6 shows a sample set of cross-stream measurements obtained using the Stereo PIV system configuration. Again velocity magnitude is plotted here as color contours, where the development of the horseshoe vortices characteristic of a jet in cross flow are readily apparent.

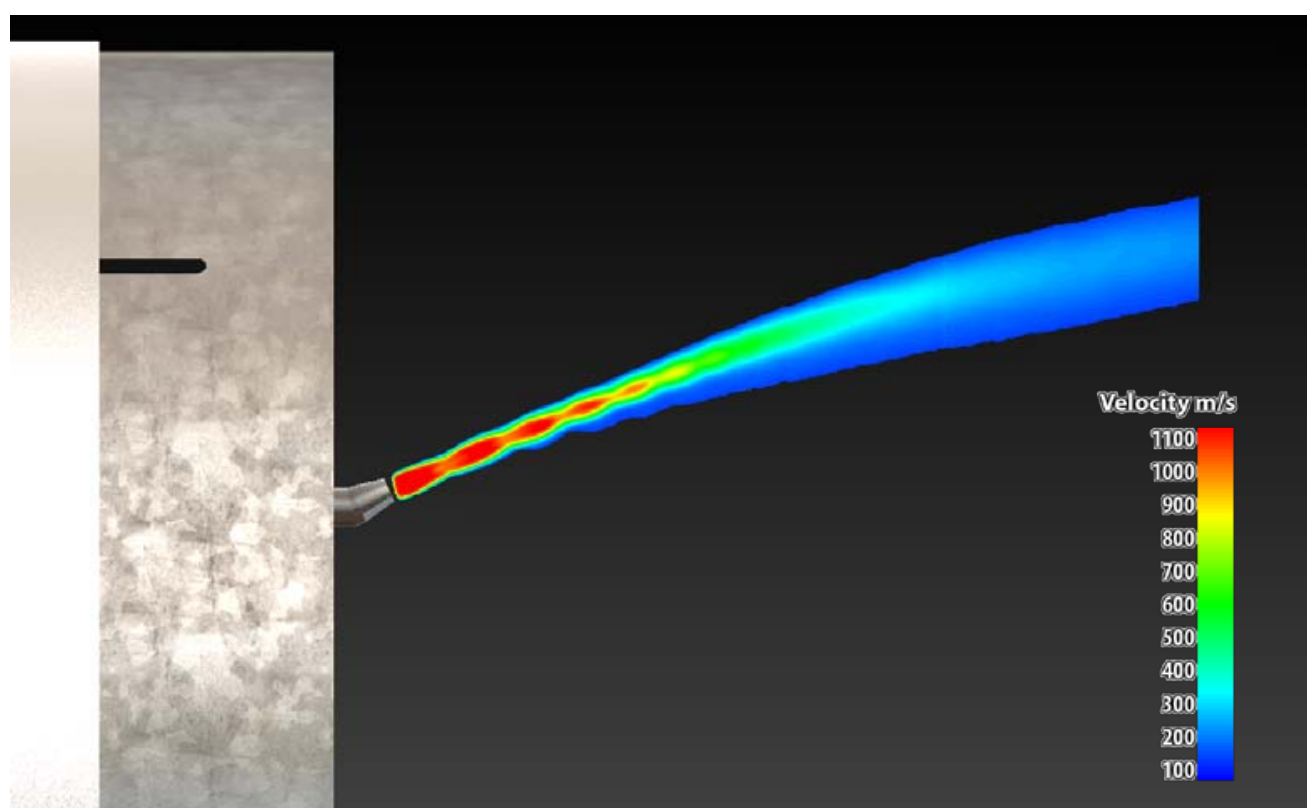

Figure 4: Velocity contours for $25^{\circ}$ Nozzle, NPR=28.5, $\mathrm{T}=1350 \mathrm{R}$.

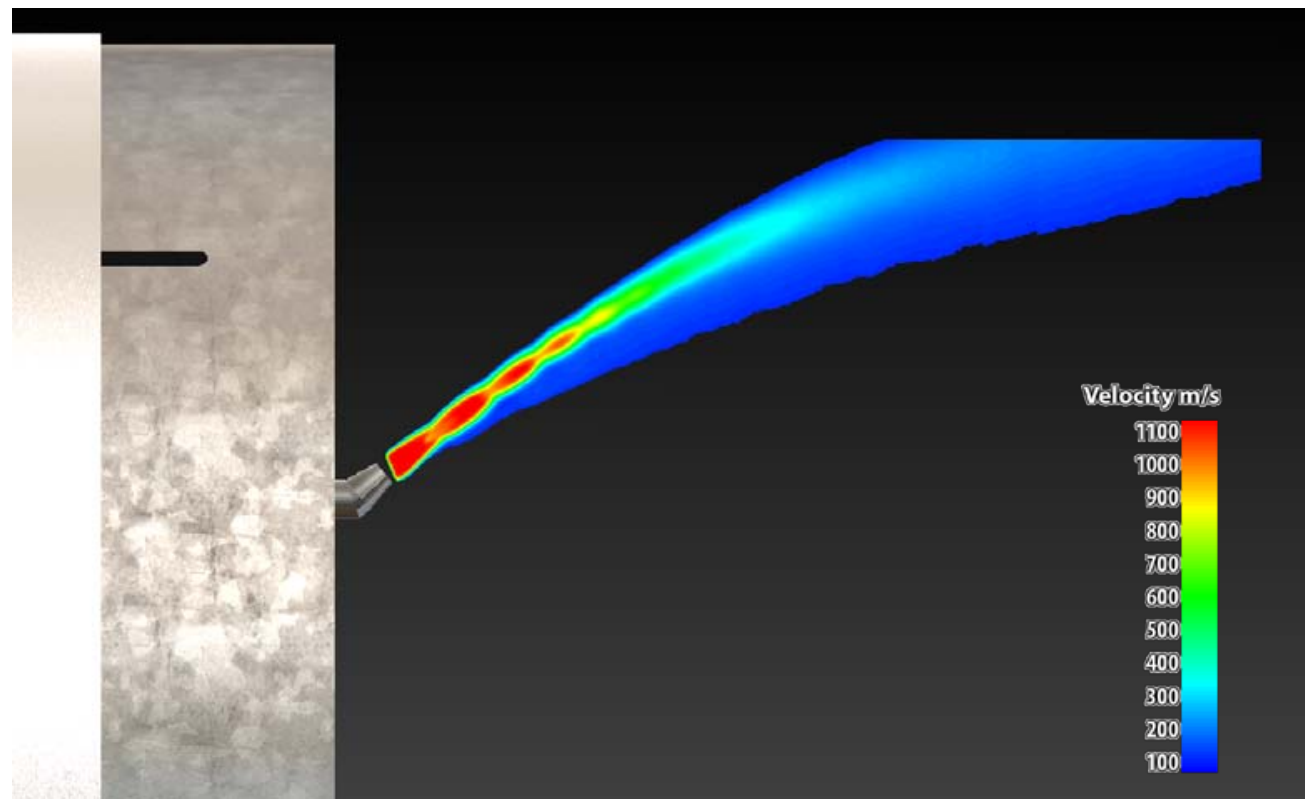

Figure 5: Velocity contours for $40^{\circ}$ nozzle, NPR=28.5, $\mathrm{T}=1350 \mathrm{R}$.

American Institute of Aeronautics and Astronautics 


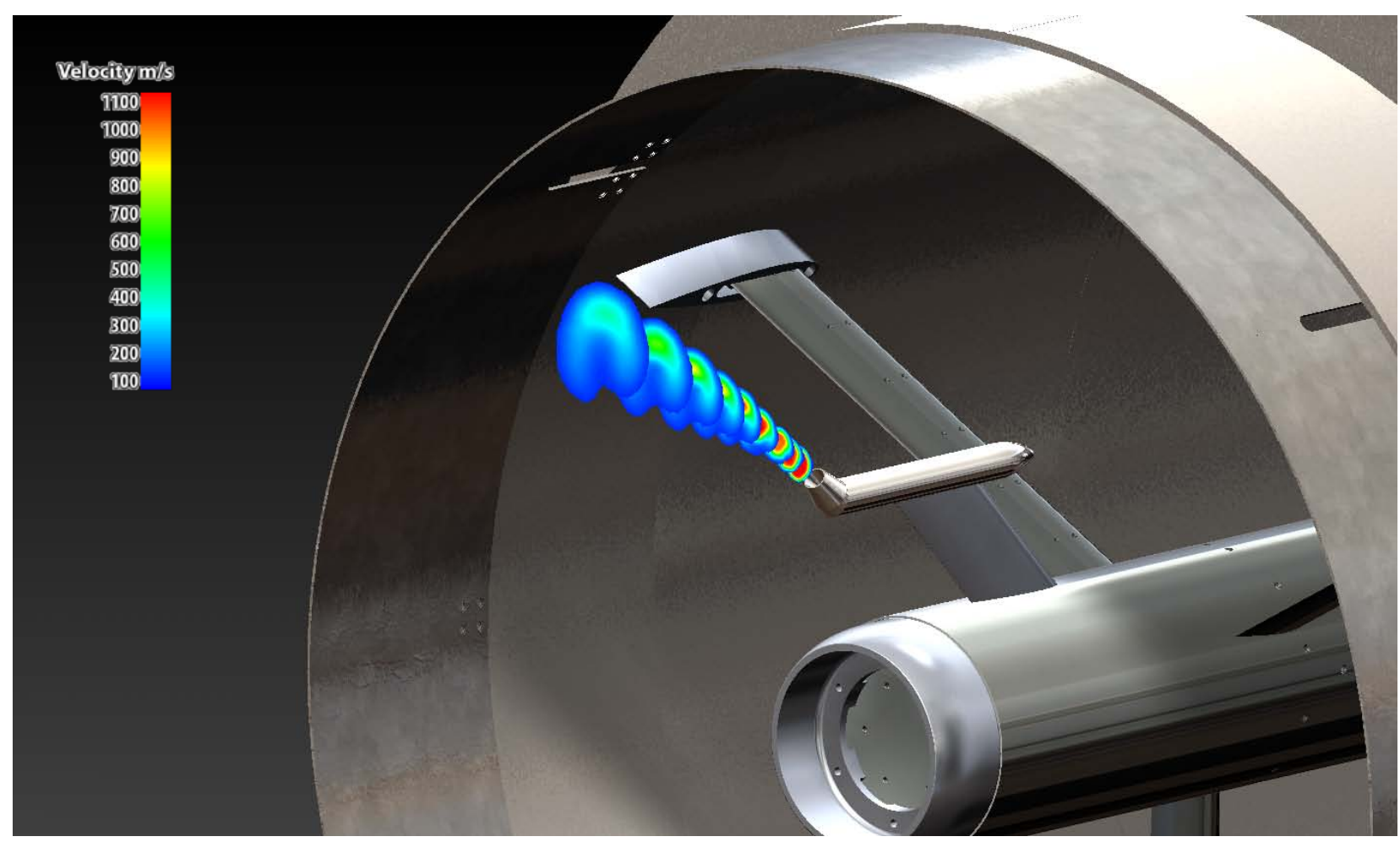

Figure 6: Perspective view of plume, velocity contours for $40^{\circ}$ nozzle, NPR=28.5, $\mathrm{T}=1350 \mathrm{R}$

\section{B. Comparison with CFD}

In the full LAV CFD studies, which predicated these experiments, the SST, Lag and Baldwin-Barth turbulence models were all applied - but not the SST-CC, since the compressibility correction was only added after comparing the SST results on the AM with the PIV results. For our comparison here on the AM model, only two turbulence model solutions have been computed to date: the SST turbulence model and the compressibility corrected SST (SST-CC) model. Figures 7 and 8 show the velocity magnitude for the SST and SST-CC predictions for the $25^{\circ}$ nozzle compared to the PIV axial plane survey measurements. In these figures, the underlying color contours are the PIV data while the overlaid black contour lines are the CFD predictions. The legend scale for both the PIV data and the CFD predictions are identical and the minimum and maximum black contour lines are called out for clarity. The slight, low velocity magnitude vertical bands in the PIV data are an artifact of stitching the individual data sets obtained from traversing of the PIV system along the jet axis together into one large data set. The black SST solution contours in figure 7 are well aligned with the PIV measurements for the first two shock cells and then they become misaligned. The SST-CC contours in figure 8 are well aligned with the PIV measured shock cell locations for the full length of the potential core.

Figure 9 shows the location of the cross-stream SPIV measurement planes, which are the locations for the comparison with the CFD results. Figure 10 compares the cross-stream SPIV results shown as color contours and the CFD results shown as overlaid black contour lines. The plots on the left are the results from the SST-CC turbulence model while the ones on the right are from the standard SST model. The CFD prediction contours do not always span the same range as the SPIV results - note the maximum contours in the figures. As can be seen in the slices, the shape of the black line contours show that the SST-CC model over predicts the vorticity, leading to a skewed plume shape and too much roll-up downstream (as depicted by the well defined, tall and narrow lobes on each side of the plume and the low velocity core between the lobes). The shape of the plume predicted with the SST model better matches the PIV data, but the velocity decays much more rapidly, as denoted by the lower max velocity black contour lines for z/D $>9$. 


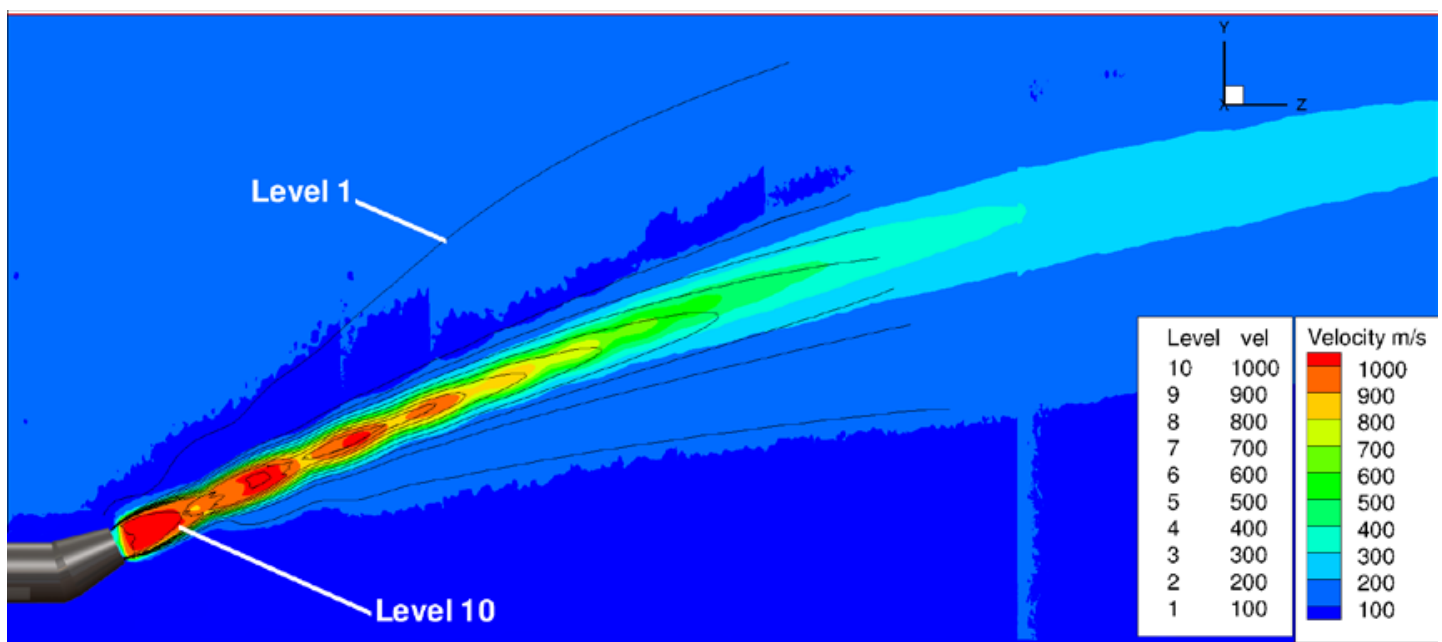

Figure 7: SST versus PIV for $25^{\circ}$ nozzle, no capsule, NPR=28.5, $\mathrm{T}=1350$. PIV results are the color contours while the SST turbulence model results are shown as black contour lines.

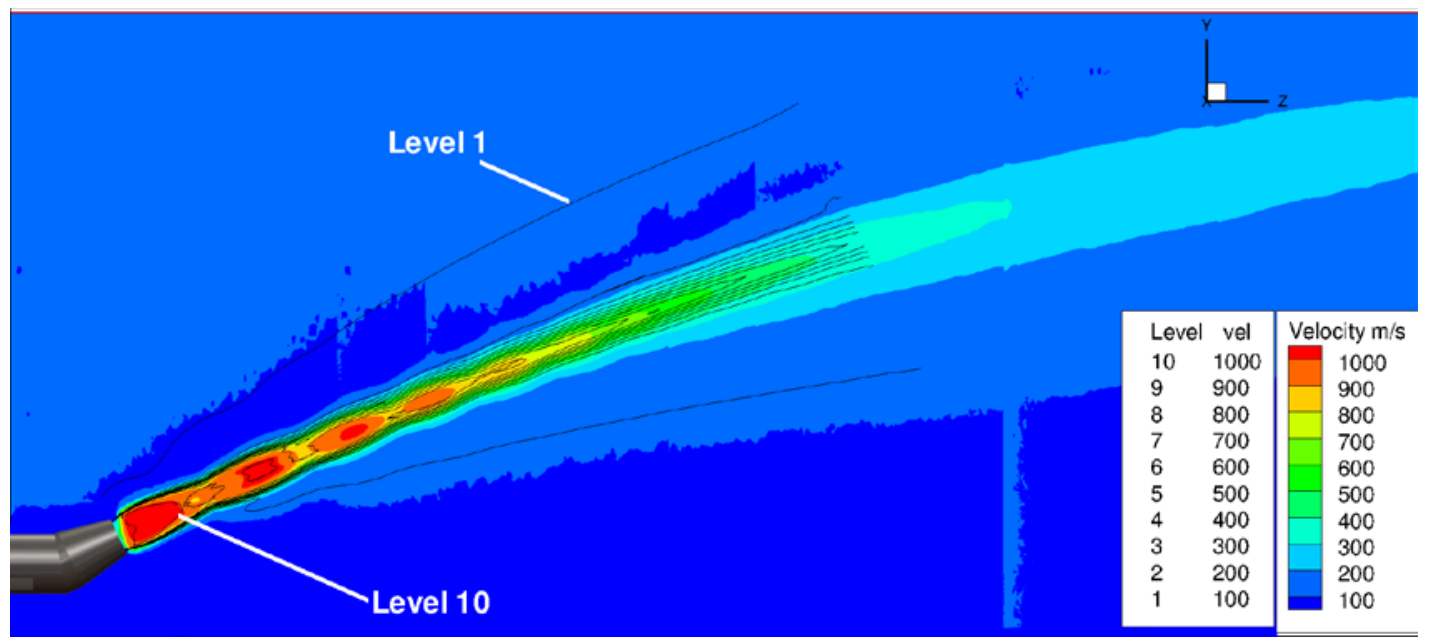

Figure 8: SST-CC versus PIV for $25^{\circ}$ nozzle, no capsule, NPR=28.5, $\mathrm{T}=1350$. PIV results are the color contours while the SST-CC turbulence model results are shown as black contour lines.

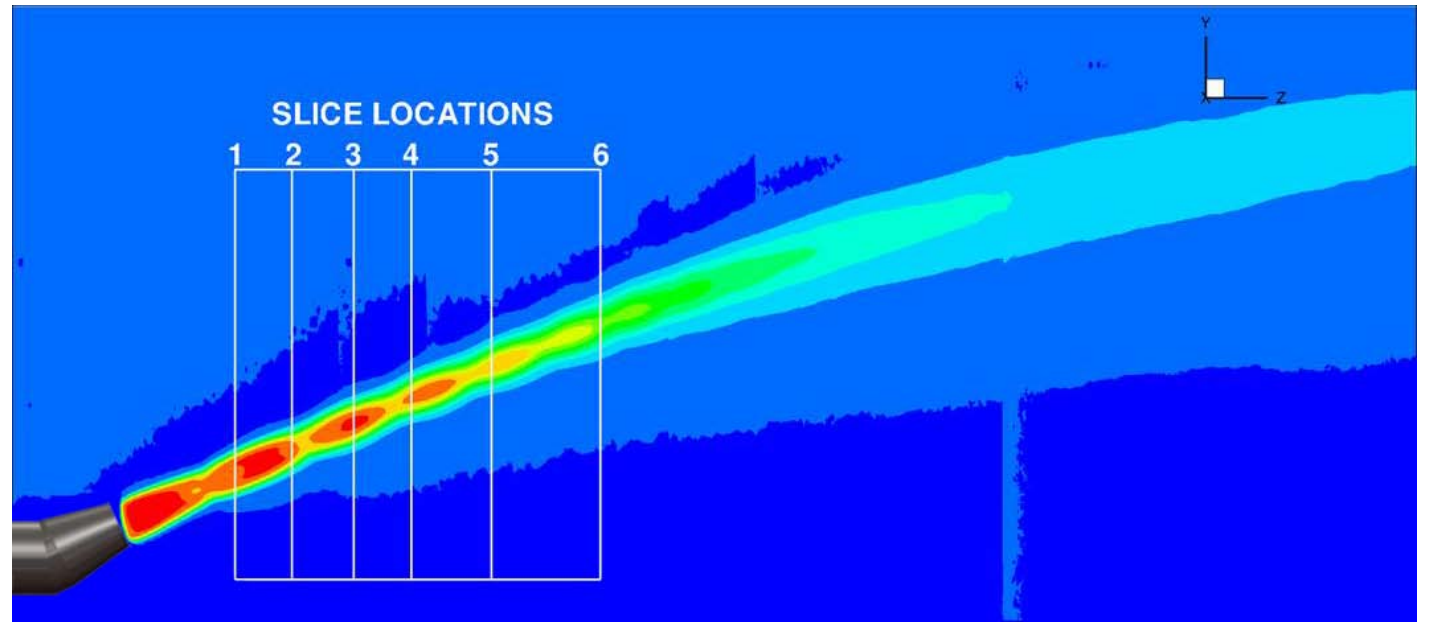

Figure 9: Locations of the cross-stream PIV measurements for figure 10. The actual normalized measurement plane locations are z/D: 2.35, 3.95, 5.54, 7.14, 9.19, 12.04 .

American Institute of Aeronautics and Astronautics 


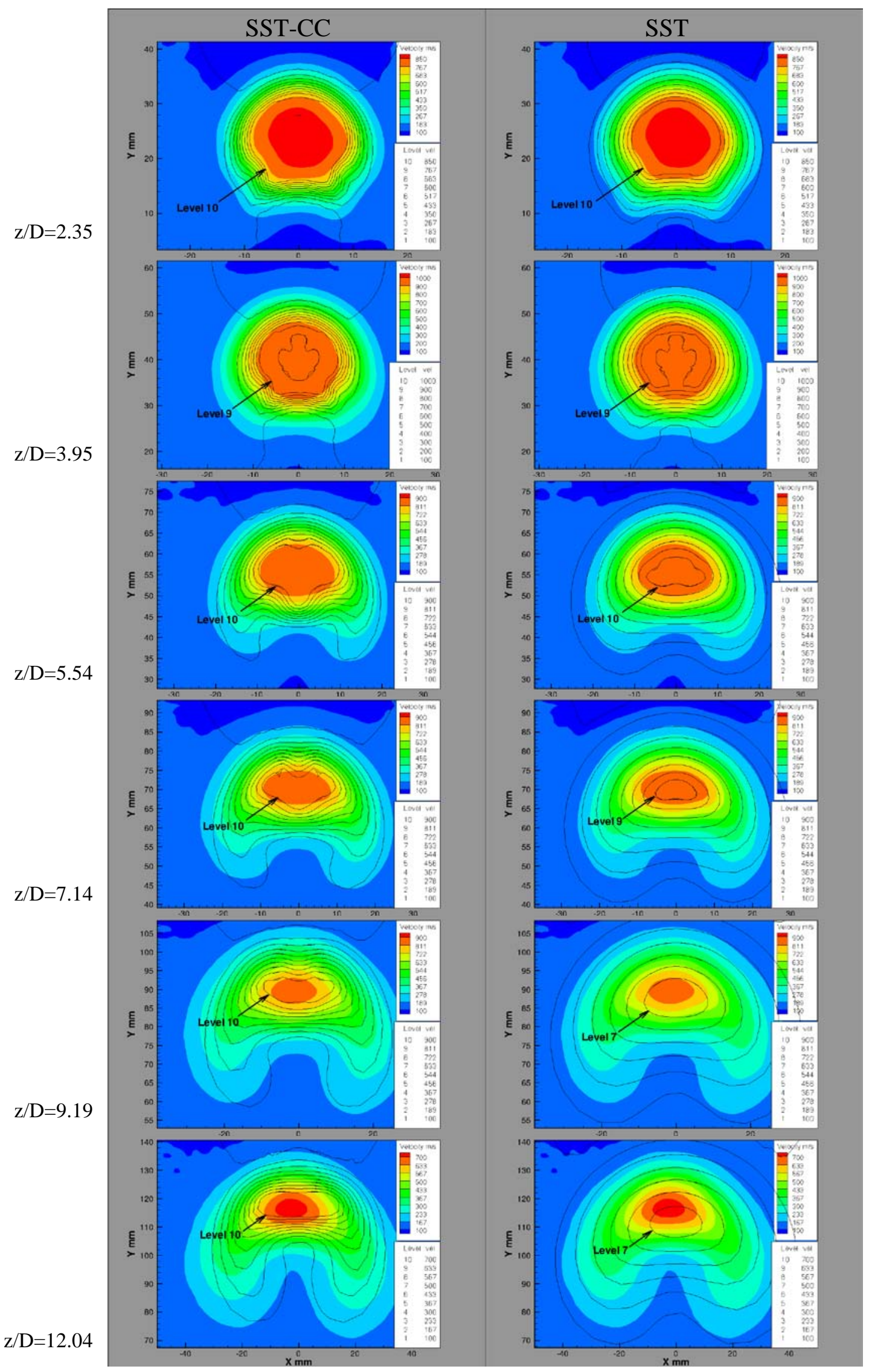

Figure 10: Cross-stream PIV data compared to CFD results. PIV data are color contours and SST and SST-CC results are overlaid as black line contours. 9 American Institute of Aeronautics and Astronautics 
In summary, the CFD simulation guidelines for the Orion program currently state the use of the standard SST model (without compressibility corrections). The comparison with the PIV data for the $25^{\circ}$ nozzle show that although the SST-CC model matches the number of shock cells in the axial cut, in the cross-stream slices we observe that it over predicts the vorticity, leading to a skewed plume shape and too much roll-up downstream. Neither model predicts the plume exactly, with the PIV data lying somewhere in between the two models. Similar results were obtained for the $40^{\circ}$ nozzle case. The SST model persists as the primary prediction while we continue research to quantify the uncertainties in the SST model.

\section{Conclusions}

The NATR facility at the NASA Glenn Research Center was used to simulate analog flow conditions for the CEV Abort Motor, both with and without the capsule in the flow. Both 2-component PIV axial plane and 3-component cross-stream SPIV measurements were acquired on the AM model and compared to SST and SST-CC turbulence model predictions.

The comparison with the PIV data shows that although the SST-CC model matches the number of shock cells in the axial cut, it over predicts the vorticity, leading to a skewed plume shape and too much roll-up downstream. The SST model under predicts both the shock cell structure and vorticty and the predicted nozzle plume decays more rapidly than the PIV measured plume. Neither turbulence model predicts the plume exactly, with the PIV data lying somewhere in between. The SPIV data collected here provide a valuable database of jet in cross-flow measurements for assessing the fidelity of CFD predictions. Work continues on developing the SST model and assessing the uncertainties in the predictions obtained with this turbulence model.

\section{Acknowledgements}

The authors would like to acknowledge the support of the Orion Program office. We would also like to thank James Bridges for the use of the NATR facility, the NATR facility support staff and the engineering design staff for their efforts to expedite the test program in order to meet the Orion program objectives. We also acknowledge the efforts of Mr. Garret Clayo and Mr. Pete Eichele in the setup and maintenance of the PIV system in the NATR facility.

\section{References}

${ }^{1}$ Ronald H. Soeder, Stephen P. Wnuk, and Raymond A. Loew. "Nozzle Acoustic Test Rig User Manual”, NASA TM-2006-212939, November, 2006.

${ }^{2}$ Wernet, J. H. and Wernet, M. P., "Stabilized Alumina/Ethanol Colloidal Dispersion for Seeding High Temperature Air Flows," Proceedings of the ASME Symposium on Laser Anemometry: Advances and Applications, Lake Tahoe, NV, 1994.

${ }^{3}$ Gui, L., Werely, S.T., “A Correlation-Based Continuous Window-Shift Technique to Reduce The Peak-Locking Effect in Digital PIV Image Evaluation”, Experiments In Fluids, Vol . 32, 2002, pp. 506-517.

${ }^{4}$ Wernet, M. P., "Symmetric Phase Only Filtering: a New Paradigm for DPIV Data Processing”, Measurement Science and Technology, Vol. 16, 2005, pp. 601-618.

${ }^{5}$ Taylor, J. R., An Introduction to Error Analysis, University Science Books, Oxford University Press, Mill Valley, CA., 1982, pp.142-144. 